\section{Knowledge sharing in online smoking cessation communities: a social capital perspective}

Knowledge sharing in smoking cessation $\mathrm{OHC}$

Chenglong $\mathrm{Li}$

Department of Management and Entrepreneurship, Turku School of Economics, University of Turku, Turku, Finland

Hongxiu Li

Department of Information and Knowledge Management, Tampere University, Tampere, Finland

Reima Suomi

Department of Management and Entrepreneurship, Turku School of Economics, University of Turku, Turku, Finland, and

Yong Liu

Department of Information and Service Management, Aalto University School of Business, Helsinki, Finland

\begin{abstract}
Purpose - Although knowledge sharing in online communities has been studied for many years, little is known about the determinants for individuals' knowledge sharing in online health communities (OHCs) surrounding smoking cessation. Examining the determinants of knowledge sharing in such OHCs from the social capital perspective may prove particularly enlightening.

Design/methodology/approach - A questionnaire-based online user survey of two smoking cessation OHCs, one based in Finland and one based in China, was performed. Performing data analysis with partial least squares (SmartPLS 3.0), the authors developed a model conceptualizing the structural, cognitive and relational dimensions of social capital as drivers for knowledge sharing in smoking cessation OHCs, with users' stage in giving up smoking as a moderator.

Findings - The results show that structural capital (social ties) and relational capital (reciprocity) are important motivators behind knowledge sharing in smoking cessation OHCs, and the authors found a moderating effect of the stage in quitting on the antecedents' relationship with knowledge sharing in these OHCs.

Originality/value - The study enriches understanding of knowledge sharing in smoking cessation OHCs, contributing to theory and identifying practical implications for such groups' administration.
\end{abstract}

Keywords Online health community, Knowledge sharing, Social capital, Smoking cessation

Paper type Research paper

\section{Introduction}

With the popularity of Web 2.0, millions of smokers have turned to the Internet for help in quitting (Graham and Amato, 2019), with one avenue being participation in online health

(C) Chenglong Li, Hongxiu Li, Reima Suomi and Yong Liu. Published by Emerald Publishing Limited. This article is published under the Creative Commons Attribution (CC BY 4.0) licence. Anyone may reproduce, distribute, translate and create derivative works of this article (for both commercial and noncommercial purposes), subject to full attribution to the original publication and authors. The full terms of this licence may be seen at http://creativecommons.org/licences/by/4.0/legalcode

The authors are grateful to the editor and the anonymous referees for their insightful comments. This work is supported by the grant from the Finnish Foundation for Economic Education (Liikesivistysrahasto) (No. 16-9095).
Received 4 March 2020 Revised 25 January 2021 5 July 2021

Accepted 7 July 2021 
INTR 32,7

112

communities (OHCs) designed for this aim (Graham et al., 2015). Smoking cessation OHCs are collectives of people who interact with each other over the Internet to give up smoking (Mpinganjira, 2018). Smoking cessation OHCs provide support differently from offline venues (e.g. face-to-face one-on-one counseling or group-based behavior therapy): OHCs provide around-the-clock access to an extended social network of ex-smokers and current smokers who share similar smoking cessation experiences, and the interaction with peers in these communities can be anonymous. Users may share their experience of the process of quitting, related struggles and support for others in the OHCs without disclosing their identity. Furthermore, smoking cessation OHCs can offer a setting free of the social stigma (discrimination, prejudices and shame) that can arise from social pressure against smoking (Brown-Johnson and Popova, 2016; Castaldelli-Maia et al., 2016). For instance, 8\% of respondents in research by Stuber and Galea (2009) reported concealing their smoking status from a health provider because of concerns about smoking-related stigma. In contrast, smoking cessation OHCs that promise anonymity may offer an empathic environment where smokers can share quitting-related information and support each other.

Studies have found that participating in smoking cessation OHCs may lead to positive smoking cessation outcomes, such as achieving 30-day point-prevalence abstinence after short-term use of the OHCs (Graham et al., 2015) and preventing relapse (Cheung et al., 2015). These advantages notwithstanding, questions remain as to what motivates users to share their knowledge of smoking cessation in smoking cessation OHCs, which is critical for the success of online communities (Chiu et al., 2006). Thus, it is important to investigate knowledge sharing behavior in smoking cessation OHCs.

While knowledge sharing in online communities has been subject to research in various contexts (e.g. Chai et al., 2011; Chiu et al., 2006; Mojdeh et al., 2018; Zhao et al., 2016), smoking cessation $\mathrm{OHCs}$ have been largely ignored thus far. One factor that sets these online communities apart from others is a shared aim of eliminating what the members share in common; that is, most users of smoking cessation OHCs are smokers who want to stop using tobacco products. Some of them might doubt their chances of success in quitting because of past failures in this regard and hence turn to the $\mathrm{OHC}$ for support, to improve their confidence and coping skills as they attempt to kick the habit. Also, a smoker may suffer from unpleasant withdrawal symptoms during the smoking cessation process, such as irritability, headaches and cravings, and specific personalized information from smoking cessation $\mathrm{OHCs}$ might be able to aid in dealing with such struggles in smoking cessation, beyond what general guidelines smoking cessation professionals offer. Unlike clinical diseases that rely primarily on physical treatments and medications, smoking cessation could be achieved via nonpharmacological interventions, such as interacting with counselors or peers (Maseeh and Kwatra, 2005). The psychological or emotional additions to smoking can be addressed from negative (such as sadness and fear) to positive (such as joy and pleasure) by engaging in online social networks (Granado-Font et al., 2018). Given smokers' unique features and needs, the motivation beyond their knowledge sharing in smoking cessation OHCs might differ from those in other online communities.

As the literature shows, knowledge sharing in online communities involves social interactions among people in online social networks, and social capital has been posited to be an important determinant of knowledge sharing in this context (Chiu et al., 2006; Wasko and Faraj, 2005). However, researchers have reported conflicting findings on motivations for knowledge sharing when studying different online communities from the social capital view. For instance, some scholars found a positive impact of relational capital (e.g. reciprocity) on knowledge sharing in the context of blog (Chai et al., 2011) and general online communities (Chang and Chuang, 2011), whereas some research reported a negative impact of relational capital (e.g. reciprocity) on knowledge sharing in professional online communities (Wasko and Faraj, 2005) or no impact in commercial online communities (Wiertz and de Ruyter, 2007). 
And prior research also reported a positive impact of cognitive capital (such as shared language) on knowledge sharing in general OHCs (Zhou, 2019) but no significant impact in specialized OHCs (Zhao et al., 2016). Hence, more context-aware theorizing is called for in knowledge sharing research (Sergeeva and Andreeva, 2016). This could uncover both differences and common patterns.

In the context of smoking cessation OHCs, past studies have examined knowledge sharing mainly from the technology (e.g. Li, 2020; Li et al., 2021) and the content perspectives (e.g. Zhang and Yang, 2015). While prior research has investigated the effects of social capital on knowledge sharing in different contexts (e.g. Chai et al., 2011; Chiu et al., 2006; Mojdeh et al., 2018; Zhao et al., 2016), relatively little attention has been paid to the specific context of smoking cessation OHCs. All these factors point to a need to study whether social capital built in smoking cessation OHCs can help explain individuals' knowledge sharing behavior in the specific context of smoking cessation OHCs.

According to the trans-theoretical model of behavior change (TTM) (Prochaska and Velicer, 1997), smokers pass through a distinct series of cessation stages before successfully quitting. Smokers have been argued to differ in their characteristics and information needs between stages (Prochaska et al., 2004; Thrul et al., 2015). However, few studies have empirically explored whether the impact of social capital on knowledge sharing in smoking cessation $\mathrm{OHCs}$ varies among smokers across smoking cessation stages. Hence, we examined the smoking cessation stage as a possible moderator when exploring the relationships involving social capital and knowledge sharing in smoking cessation OHCs.

To address the aforementioned gaps, we developed a research model based on social capital theory (Nahapiet and Ghoshal, 1998). For investigating the determinants of knowledge sharing in smoking cessation OHCs, we then tested the proposed model empirically via 173 online survey responses from users of smoking cessation OHCs in Finland and China. This work shed light on individual users' knowledge sharing behavior from the social capital perspective and the posited moderating effect of users' stage in quitting on the impact of social capital on that behavior in smoking cessation online communities.

We begin our discussion with a review of prior literature on knowledge sharing in smoking cessation OHCs and social capital theory. Then, we present the hypotheses and research model. Against this backdrop, we describe the research methods and discuss the results. The paper concludes with thoughts on theoretical and practical implications, alongside the identification of the work's limitations and further opportunities.

\section{Theoretical background}

Knowledge sharing in smoking cessation OHCs

The concept of knowledge sharing refers to an individual disseminating the knowledge, skills or experiences he or she has obtained with others (Hsu et al., 2007). The information systems (IS) literature includes investigations of knowledge sharing in various online contexts, such as online communities for legal professionals (Wasko and Faraj, 2005), blogs (Chai et al., 2011), web-based discussion communities (Ray et al., 2014) and general-purpose OHCs (Zhang et al., 2017b).

Smoking cessation OHCs are like other online communities in that knowledge sharing is their core activity and also vital for the sustainable development of the OHC. Those studies investigating knowledge sharing in a smoking cessation context have taken various perspectives. One focus has been on identifying what has been shared in smoking cessation $\mathrm{OHCs}$ by applying content analysis to the sharing activities in these groups. For instance, the work of Myneni et al. (2016) identified the following 12 themes: social support, traditions, progress, cravings, motivation, benefits, virtual rewards, relapse, obstacles, nicotine replacement therapy specifically, friends and family members and conflict; in contrast,
Knowledge sharing in smoking cessation $\mathrm{OHC}$

113 
INTR 32,7

114
Cheung et al. (2017) classified the topics of sharing in smoking cessation OHCs on WhatsApp and Facebook platforms into three main types: sharing views and experience (55.5\%), encouragement $(28.7 \%)$ and knowledge and information (15.8\%). The predominant framework applied in these studies for exploring the sharing behavior among the users has been social support theory, and knowledge sharing has been identified as one important activity alongside sharing of emotional support, esteem support and network support (Cheung et al., 2017; Granado-Font et al., 2018).

Another stream of research has focused on users' knowledge sharing patterns in smoking cessation OHCs. For instance, Ploderer et al. (2013) found that users at different stages of quitting manifest different patterns of knowledge sharing in these OHCs. Specifically, those at later stages in quitting mainly make comments in the smoking cessation $\mathrm{OHCs}$, whereas the supportive responses and leadership come mainly from users who have just started the process. Investigating the knowledge sharing patterns in smoking cessation $\mathrm{OHCs}$ from a social support perspective, in turn, Zhang and Yang (2015) found that those who share knowledge to provide information support have typically been abstinent for a longer time than those who give emotional, esteem and network support. For instance, users further along in quitting exhibit a preference for sharing more advice and personal experiences with users who are in the early stages.

Some scholars have attempted to investigate the motivations for knowledge sharing in smoking cessation OHCs. Such as Li et al. (2021) have identified the perceived usefulness of smoking cessation OHCs as an important determinant of knowledge sharing. Li (2020) discovered a positive correlation between user satisfaction with smoking cessation $\mathrm{OHCs}$ and knowledge sharing. Table 1 lists some literature on knowledge sharing in smoking cessation $\mathrm{OHCs}$.

As shown in Table 1, the prior literature examines knowledge sharing behavior principally from the content and technology perspectives, and the role of social relationships in knowledge sharing in smoking cessation $\mathrm{OHCs}$ has been ignored, notwithstanding literature stating that social relationships are important reasons for knowledge sharing in online communities in general. In addition, most of these studies have applied qualitative research methods, and research in a quantitative manner is very limited. Prior research suggests that social capital theory may hold value for explaining consequences of social relationships and community connections (Bartelt et al., 2020; Cabrera and Cabrera, 2005; Choi, 2015). This points to a need to investigate what motivates knowledge sharing in smoking cessation OHCs from the social capital perspective.

\section{Social capital theory}

With its roots in community studies, social capital theory focuses on the resources derived through interpersonal relationships among people. Nahapiet and Ghoshal (1998, p. 243) defined social capital as "the sum of actual and potential resources embedded within, available through, and derived from the network of relationships possessed by an individual or social unit" and "[s]ocial capital thus comprises both the network and the assets that may be mobilized through that network." Social capital theory has been widely applied to investigate the effect of resources on social relationships in our lives from both individuals' and organizations' perspective in various fields, with examples being the research contexts of health promotion (Wakefield and Poland, 2005) and management (Leana and Van Buren, 1999; Nahapiet and Ghoshal, 1998). In general, prior literature points to an association between social capital and a host of positive outcomes, such as better health at the level of the individual and improved performance of organizations (Adler and Kwon, 2002).

Social capital theory has been applied specifically to knowledge sharing from both the individual and the organization's angle. Scholars have posited that it provides a framework to 

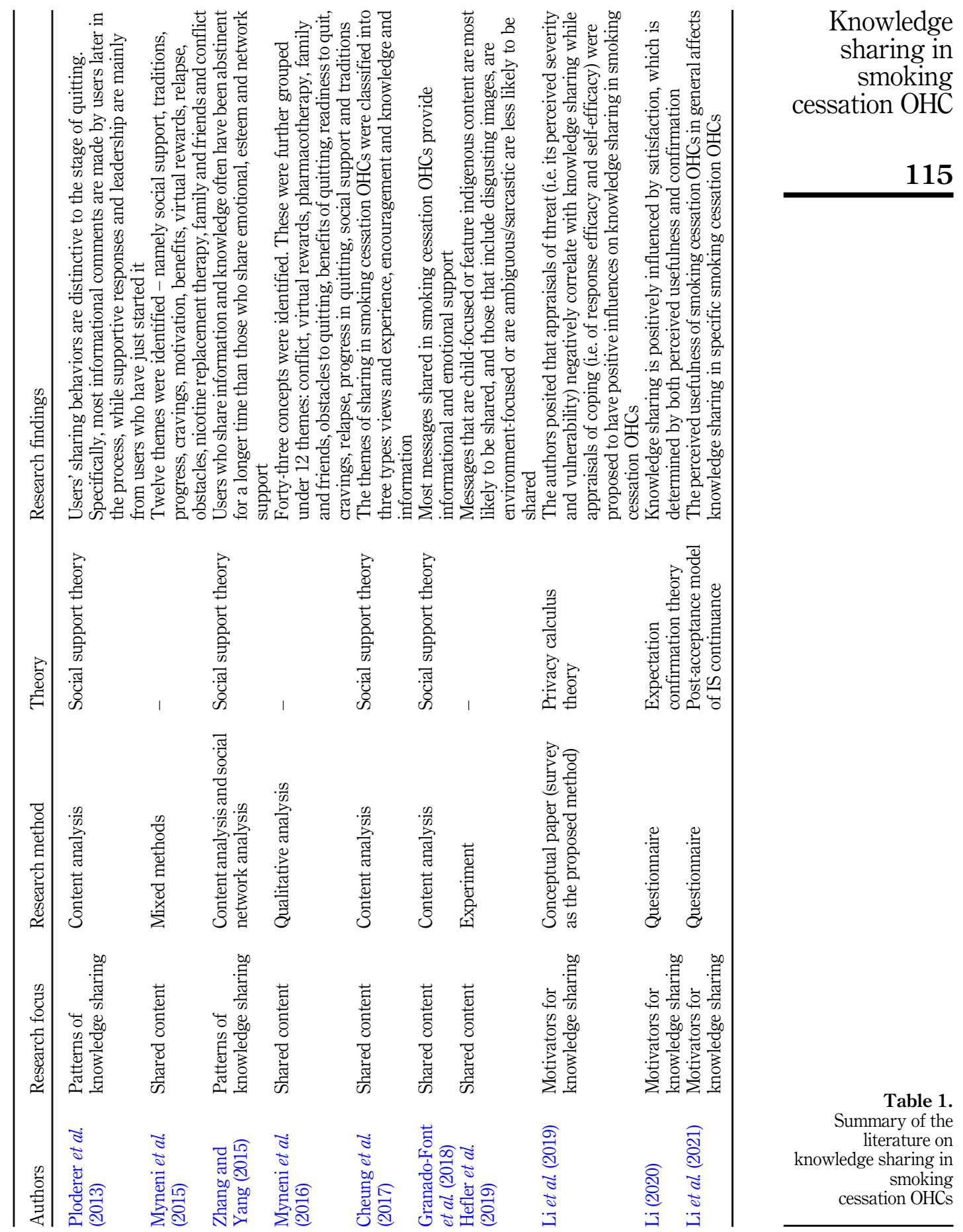

Table 1.

Summary of the literature on smoking cessation $\mathrm{OHCs}$ 
INTR 32,7

\section{6}

explain knowledge sharing mainly in terms of three dimensions: structural, relational and cognitive capital (Chiu et al., 2006; Wasko and Faraj, 2005). The first refers to the overall structure of connections among people and is regarded as the channel for information flows (Tsai and Ghoshal, 1998). Researchers measure it by evaluating patterns and density characteristics of social networks, such as centrality (Wasko and Faraj, 2005) and social ties (Chiu et al., 2006). The notion of relational capital brings in the affective nature of the relationships within a social network, such as trust, reciprocity and commitment (Chiu et al., 2006; Wasko and Faraj, 2005). Finally, cognitive capital denotes resources providing shared interpretations and meanings within a social network, such as a shared language and vision (Chiu et al., 2006).

The three dimensions of social capital have been applied to explore knowledge sharing in numerous contexts, among them a profession-based online community (Wasko and Faraj, 2005), IT-oriented online communities (Chiu et al., 2006), firm-based commercial online communities (Wiertz and de Ruyter, 2007), blog sites (Chai et al., 2011), online games' user communities (Hau and Kim, 2011), work teams (Yu et al., 2013), firms (Chow and Chan, 2008; Hau et al., 2013), OHCs (Zhang et al., 2017a; Zhao et al., 2016) and social networking site (SNS) contexts (Mojdeh et al., 2018). For instance, examining an online community of legal professionals, Wasko and Faraj (2005) found both structural and cognitive capital to play important roles in knowledge sharing, while relational capital was not a significant motivator of knowledge sharing. As for OHC settings, structural capital (i.e. network density) has been found to enhance both the externalization and the combination aspect of knowledge creation (Zhao et al., 2016). In a similar vein, SNS research by Mojdeh et al. (2018) revealed that one factor in relational capital (i.e. identification) has a positive influence on knowledge sharing intention, while the other factor considered (i.e. reciprocity) is only marginally significant. Table 2 presents more details on the research findings connected with the three dimensions of social capital in the field of knowledge sharing.

We selected social capital theory as our theoretical framework for investigating knowledge sharing for several reasons. Firstly, social capital theory highlights the role of social capital in obtaining different resources to benefit individuals and organizations (Bartelt et al., 2020; Ellison et al., 2006; Nahapiet and Ghoshal, 1998). Prior research suggests that this theory may hold value for explaining the outcomes obtained due to social relationships and community connections (Bartelt et al., 2020; Cabrera and Cabrera, 2005; Choi, 2015). Secondly, social capital has been identified as a central theme in explaining knowledge sharing based on the social relationships and community connections inherent to online communities (Chiu et al., 2006; Wasko and Faraj, 2005). This ties in with the aim of investigating the knowledgesharing behavior of individual users in the context of smoking cessation OHCs in this study. Thirdly, smoking cessation $\mathrm{OHCs}$ are collectives of people who have similar concerns about quitting and who are embedded in social networks formed in online communities. Individual users can develop social capital via social interactions with others in online communities. This renders social capital theory suited to explaining knowledge sharing in smoking cessation OHCs. Taking it as a basic theoretical framework for the study, we followed established literature in applying the three-dimensional model of social capital for investigating the knowledge sharing in question.

\section{The research model and hypotheses}

Development of the model

Prior research indicates that social capital is one of the main factors in individuals' sharing of knowledge in online communities (Chai et al., 2011; Chang and Chuang, 2011; Chiu et al., 2006; Mojdeh et al., 2018; Nahapiet and Ghoshal, 1998; Zhao et al., 2016). Below, we explain how we developed our use of the framework to address the research phenomenon in light of previous 


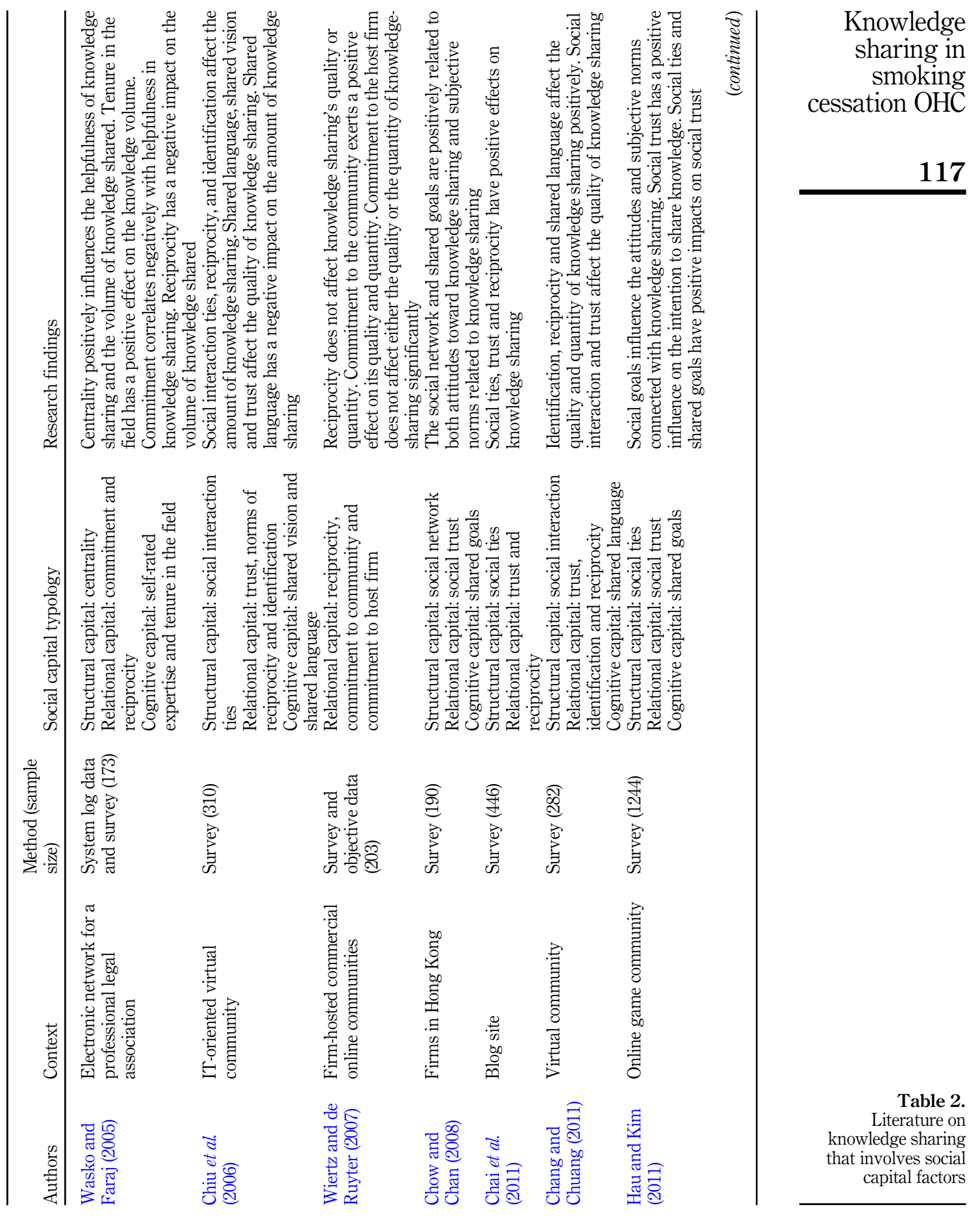


INTR
32,7

118
Table 2.

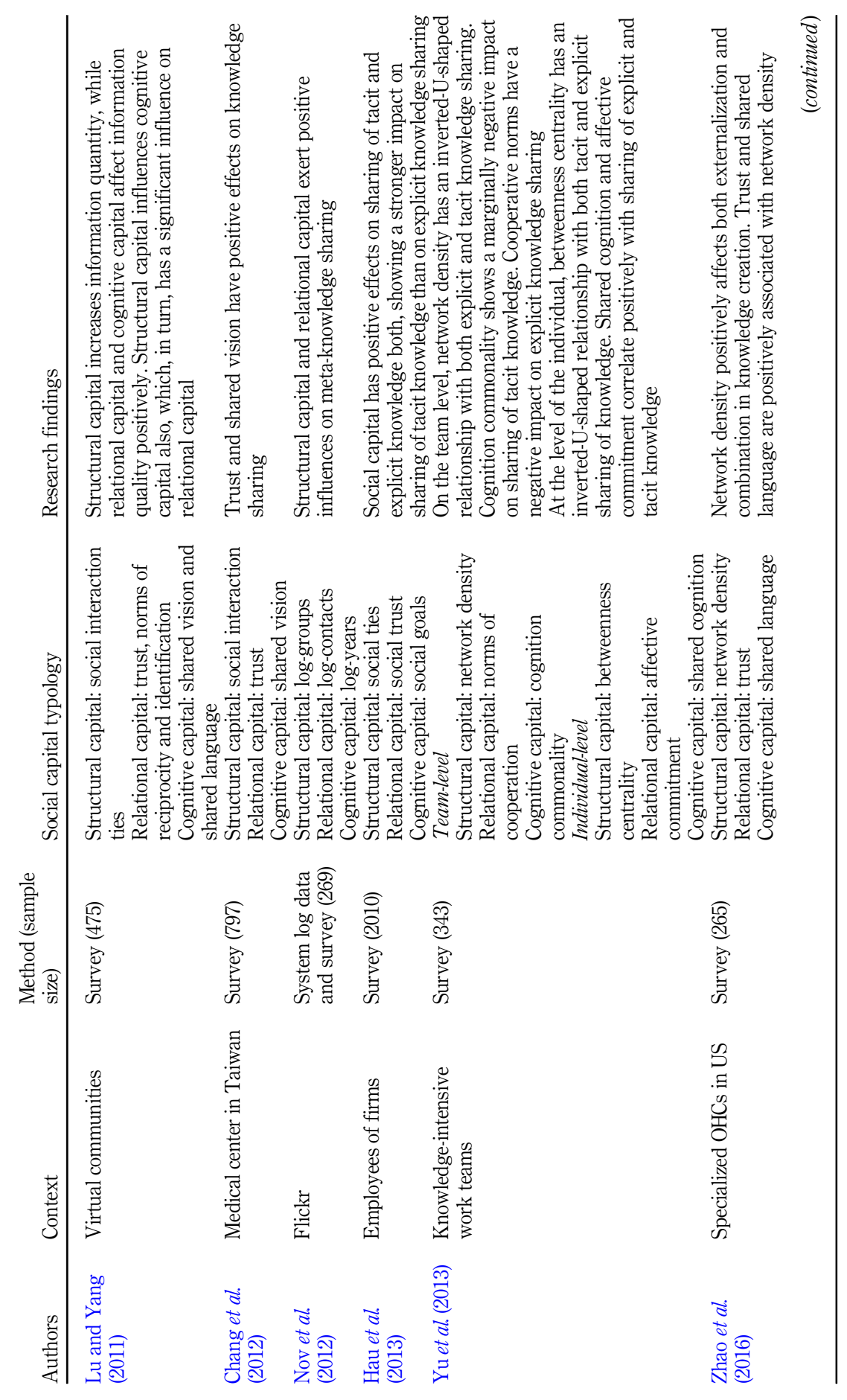



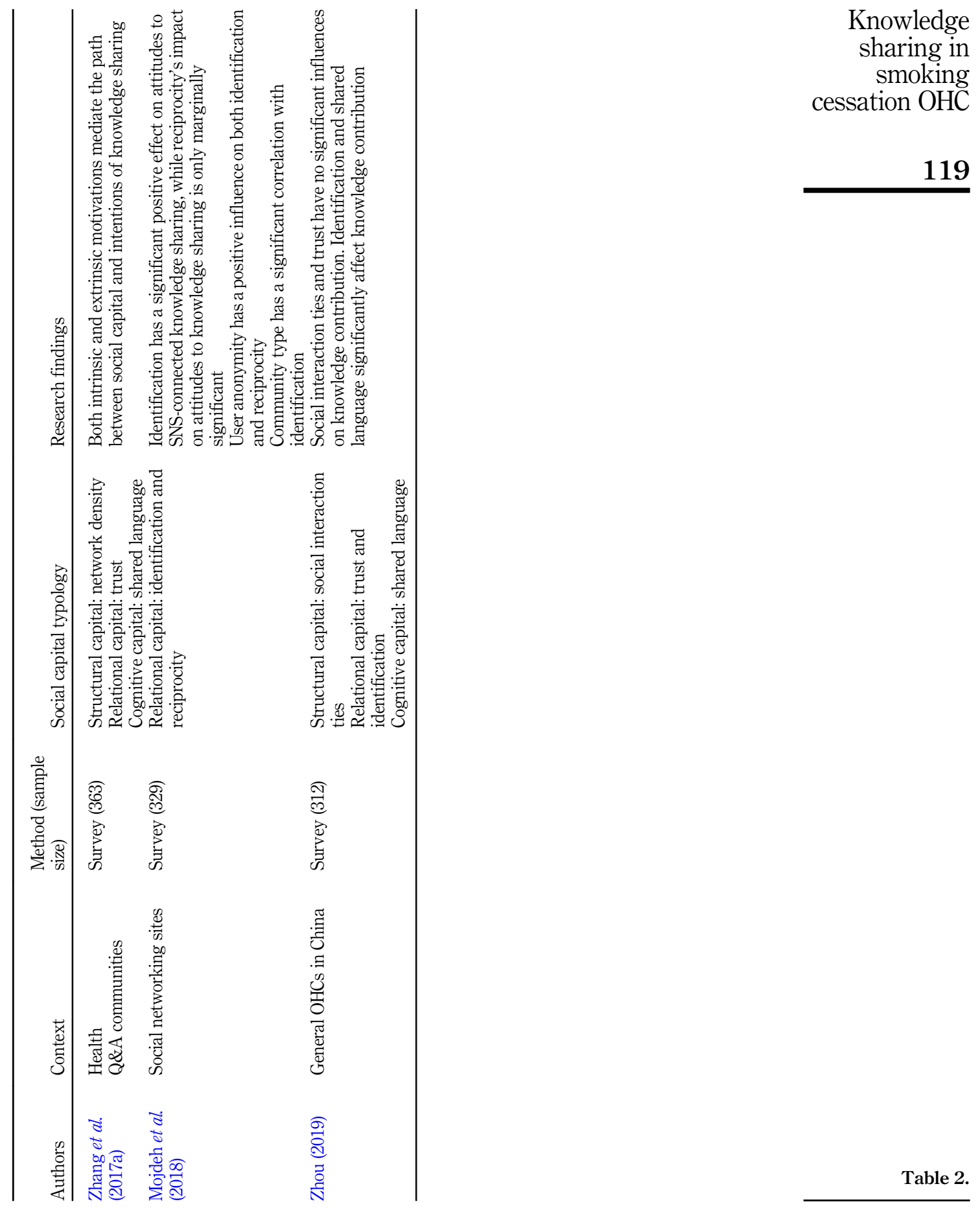

Table 2. 
INTR 32,7

120

findings on the impact of the dimensions of social capital on knowledge sharing at the level of the individual, and Table 3 lists the definitions of the constructs included in the research model.

As noted above, users of a smoking cessation $\mathrm{OHC}$ interact and establish connections with others even though they are anonymous. For instance, they post messages to seek help, reply to others' questions or comment on others' achievements. The users are connected with the other members of the smoking cessation $\mathrm{OHC}$ via social interaction activities, and users also share information in the connected communities. In other words, they build a social bond in and with the OHCs. Studies have validated that this set of social ties is indeed a key factor reflecting structural capital (Chai et al., 2011; Chiu et al., 2006). Accordingly, we assumed that social ties are an element reflecting structural capital in smoking cessation OHCs.

Online communities also provide users with a way of building relational capital (Chiu et al., 2006; Wasko and Faraj, 2005). According to Wasko and Faraj (2005), reciprocity is an essential feature of online communities. Users of smoking cessation OHCs contribute to these communities by posting initial messages, answering questions and commenting on others' contributions. Thus, the content both benefits others and solicits help - for example, via requests for tips or advice. Thereby, reciprocity is evident in online communities. Furthermore, to realize mutuality in smoking cessation $\mathrm{OHCs}$, users must maintain their commitment to the online community (Chiu et al., 2006). The literature points to reciprocity and commitment as reflecting relational capital connected with knowledge sharing in online communities (Chiu et al., 2006; Wiertz and de Ruyter, 2007), so we presumed that the constructs of reciprocity and commitment should capture relational capital in smoking cessation OHCs.

Research has revealed that, over time, communicating with peers who have shared similar situations and experiences will help users gradually develop cognitive capital, such as shared language and a shared vision (Chang and Chuang, 2011; Chiu et al., 2006; Zhang et al., 2017a; Zhao et al., 2016). In smoking cessation OHCs, users indeed develop both shared terms/jargon and such components of a joint vision as common goals or concerns about smoking cessation. Since shared language and shared vision have been concluded to constitute the factors best capturing cognitive capital in knowledge sharing within online communities (Chang and Chuang, 2011; Chiu et al., 2006; Zhang et al., 2017a; Zhao et al., 2016), we assumed that these two factors should capture cognitive capital in smoking cessation OHCs.

\section{Hypothesis development}

Members of smoking cessation OHCs can build relationships through both asynchronous methods (e.g. one-to-one private messages or one-to-many postings in threads) and

Table 3.

Constructs included in Social ties the research model

\begin{tabular}{|c|c|}
\hline Construct & Definition \\
\hline $\begin{array}{l}\text { Knowledge } \\
\text { sharing }\end{array}$ & $\begin{array}{l}\text { The act of exchanging information, experience and skills connected with smoking } \\
\text { cessation among users within a smoking cessation OHC Hsu et al. (2007) }\end{array}$ \\
\hline Commitment & $\begin{array}{l}\text { An enduring desire to maintain the relationship with the smoking cessation OHC Wiertz } \\
\text { and de Ruyter (2007) }\end{array}$ \\
\hline Reciprocity & $\begin{array}{l}\text { A sense of a mutual debt to repay or appreciation for the benefits obtained from others in } \\
\text { the smoking cessation OHC Chiu et al. (2006) }\end{array}$ \\
\hline Shared language & $\begin{array}{l}\text { Distinctive smoking-cessation-related terms for which users share a common } \\
\text { understanding so as to facilitate communication in the smoking cessation OHC Chang } \\
\text { and Chuang (2011), Chiu et al. (2006) }\end{array}$ \\
\hline Shared vision & $\begin{array}{l}\text { Values, goals and concerns held in common with regard to smoking cessation Chiu et al. } \\
\text { (2006), Hau et al. (2013) }\end{array}$ \\
\hline Social ties & $\begin{array}{l}\text { The strength of the relationships, communication frequency and duration of } \\
\text { communication among users in the smoking cessation OHC Chiu et al. (2006) }\end{array}$ \\
\hline
\end{tabular}


synchronous ones (e.g. real-time chatrooms) (Cobb et al., 2010). The relationships among them provide cost-effective information channels suitable for sharing knowledge with thousands of ex-smokers and current smokers participating in the OHCs. These relationships may be strengthened via frequent and sustained interaction among users. The social ties are largely built upon the closeness of users' relationships with each other. Work by Chiu et al. (2006) and by Chang and Chuang (2011) has explicated that the stronger the social ties built, the greater the quantity of knowledge shared in the online community. Likewise, Chai et al. (2011) have articulated that social ties constitute a strong driver of knowledge sharing among bloggers. Proceeding from the foregoing discussion, we postulated that the stronger the social bond in smoking cessation $\mathrm{OHCs}$, the more the users will share knowledge in their smoking cessation OHC. Accordingly, we formed the following hypothesis:

H1. Social ties are positively associated with knowledge sharing in smoking cessation OHCs.

Shared language pertains to the common codes, vocabulary or understandings that users adopt in their communications, here in smoking cessation OHCs (Chang and Chuang, 2011; Chiu et al., 2006). Often, the information shared is related to the range and extent of nicotine withdrawal symptoms, medical treatments and tobacco products. However, smokers frequently are confused about the associated terminology. For instance, Alexander et al. (2016) found that, while smokers generally understand electronic cigarette products overall, the details of product types often confuse them. To build a common understanding for purposes of smoking cessation, users create common terms in many cases, such as slang that is easy to understand for members of the community - for instance, employing the commonly used "e-cigarette" and "vaping" to represent electronic cigarettes in a Twitter-based group (van der Tempel et al., 2016). In smoking cessation OHCs, shared language promotes effective knowledge sharing by offering an avenue by which users can adopt common terms connected with smoking cessation and thereby avoid certain misunderstandings. Moreover, shared language offers a template with well-established codes for new members to follow and learn, making them capable of communicating with others more readily. Research has identified shared language as a motivator that determines knowledge sharing in online communities (Chang and Chuang, 2011; Chiu et al., 2006). Likewise, we expected shared language among the users of smoking cessation $\mathrm{OHCs}$ to exert a positive influence on knowledge sharing in the communities, so we formed this hypothesis:

H2. Shared language is positively associated with knowledge sharing in smoking cessation OHCs.

A shared vision articulates common goals, values and aspirations among the users of a smoking cessation OHC (Chang et al., 2012; Chiu et al., 2006). One key part of the vision shared is to deal with difficult situations caused by the smoking habit and achieve long-term abstinence through supporting one another. The shared vision binds previously isolated smokers together and enhances interactions by such means as helping the users see the potential value of sharing medical and experiential knowledge of smoking cessation with others. Studies have validated shared vision as a significant influence on knowledge sharing in online communities (Chiu et al., 2006). The above reasoning led us to propose that shared vision is one of the main factors determining the knowledge sharing in smoking cessation OHCs, and the following hypothesis was developed:

H3. Shared vision is positively associated with knowledge sharing in smoking cessation OHCs.

Reciprocity is an important aspect of relational capital because people expect mutuality of costs in terms of effort and time devoted to contributing knowledge (Chiu et al., 2006; Wasko and
Knowledge sharing in smoking cessation $\mathrm{OHC}$ 
INTR 32,7

122

Faraj, 2005). The reciprocity expressed in smoking cessation OHCs provides users with a sense of fairness and some kind of guarantee that their contributions will be rewarded by others in the long run (Chiu et al., 2006). One would expect this pattern to hold irrespective of the use of pseudonyms, and indeed there is evidence of reciprocal interactions even though most smoking cessation $\mathrm{OHCs}$ provide anonymity. For instance, a study of a Twitter-based smoking cessation $\mathrm{OHC}$ found more than $50 \%$ of ties to be reciprocal (Lakon et al., 2016). The fairness evidenced by mutuality and reciprocity among users of smoking cessation OHCs might encourage users to contribute knowledge by replying to others' questions or promptly supplying information in the OHCs. Finally, findings in previous studies support the conclusion that reciprocity has a positive impact on knowledge sharing in online settings (Chai et al., 2011; Chang and Chuang, 2011; Chiu et al., 2006). Thus, it seemed reasonable to assume that:

H4. Reciprocity is positively associated with knowledge sharing in smoking cessation $\mathrm{OHCs}$.

Commitment entails a sense of belonging and positive feelings toward the collective, and it nurtures loyalty and citizenship-oriented behavior collectively ( $\mathrm{Yu}$ et al., 2013). How do smoking cessation $\mathrm{OHCs}$ express this? They can provide users with both informational and emotional support (Rocheleau et al., 2015), which confer a sense of being attached to the $\mathrm{OHC}$. The mutual support and the empathy embodied by the online communications with peers might further motivate a user to participate and maintain the relationship with the $\mathrm{OHC}$. Users with a high level of commitment to a smoking cessation $\mathrm{OHC}$ would be expected to possess and convey an ethos of an obligation and duty of helping others, and they are likely to remain members and share knowledge of smoking cessation with their peers in the long term. In work by $\mathrm{Yu}$ et al. (2013), considering knowledge-intensive work teams, the commitment was found to be positively correlated with knowledge sharing. The above reasoning led us to expect the commitment of the individual users to drive their knowledge sharing in smoking cessation OHCs, and we developed the following hypothesis accordingly:

H5. Commitment is positively associated with knowledge sharing in smoking cessation $\mathrm{OHCs}$.

Smokers pass through a series of distinct cessation stages before achieving long-term abstinence, characterized as precontemplation (no intention to quit), contemplation (thinking about quitting), preparation (planning to quit within the next month), action (quitting successfully within six months), maintenance (no smoking for at least six months) and termination (zero temptation and 100\% self-efficacy) (Prochaska and Velicer, 1997). Smokers' needs vary between these stages; for example, when Thrul et al. (2015) investigated a smoking cessation intervention on the Facebook platform, they found that users at precontemplation or contemplation stage were concerned more about the pros and cons of quitting while those at the preparation stage were more focused on consciousness raising. Accordingly, Prochaska et al. (2004) recommended providing smokers with information customized for their particular stage in smoking cessation, to match their personal needs. In addition, the smoking cessation stage has been found to be associated with the foci of smoking cessation behavior, such as restrictions on smoking in the home (Pizacani et al., 2008). Concentrating on a Facebook-based smoking cessation OHC, Ploderer et al. (2013) reported that the smoking cessation stage has a connection also with the social support shared in online communities, with the majority of comments being provided by those who had successfully progressed to a more advanced stage, such as people at the maintenance or termination stage.

Findings from prior research indeed suggest that the motivation for users' knowledge sharing in smoking cessation OHCs might differ with one's stage in giving up smoking 
(Ploderer et al., 2013; Zhang and Yang, 2015). For instance, for those who have not taken actions to quit smoking, such as in contemplation and preparation stages, their participation in smoking cessation OHCs might not have developed strong relationships with other users and have a strong sense of commitment and reciprocity. But they will share the similar language in the $\mathrm{OHCs}$ as well as share the similar vision supporting each other in quitting smoking in the OHCs. Thus, structural capital and relational capital might have a weaker influence on knowledge sharing than cognitive capital for these users. And those who are in the process of quitting (such as in the action stage) might have benefited from the OHCs in quitting smoking, and relational capital (such as reciprocity and commitment) might have a much stronger influence on their knowledge sharing in these OHCs than structural and cognitive capital. For those who have quit smoking (such as in maintenance and termination stages), structural capital and relational capital might have stronger impacts on their knowledge sharing than cognitive capital. They have used smoking cessation $\mathrm{OHCs}$ for a certain period of time and might have built strong relationships with other users, and they have also achieved certain success in smoking cessation, which might help them build a strong sense of responsibility and duty for them to help others via sharing their knowledge. Therefore, we considered the smoking cessation stage as a possible moderator of the proposed relationships between social capital and knowledge sharing in smoking cessation OHCs. Thus, the following hypotheses were developed:

H6. The smoking cessation stage moderates the relationship between knowledge sharing and (a) social ties, (b) shared language, (c) shared vision, (d) reciprocity and (e) commitment.

In addition, prior research has identified gender and age differences in smoking cessation (Messer et al., 2008; Wetter et al., 1999), and knowledge sharing literature also suggests that gender differences should be considered in studies in online settings (Chai et al., 2011). Since we collected data from two countries with different cultures, there might be cultural differences between the two user groups participating in this study. Therefore, we set age, gender and country as control variables in the proposed research model. Figure 1 presents the

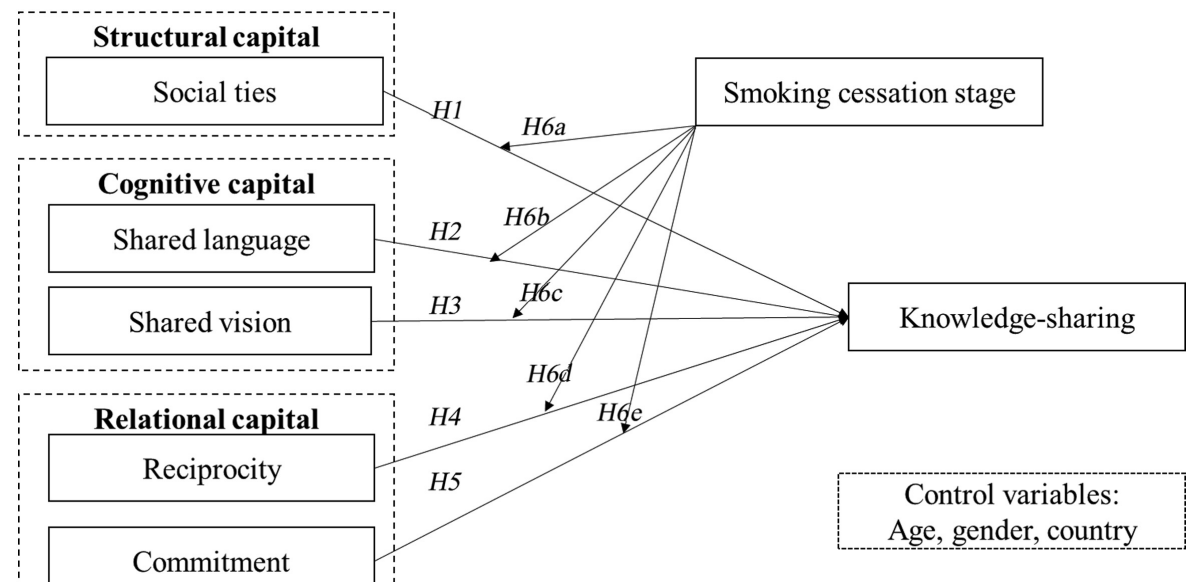

\section{proposed research model and hypotheses.}

Knowledge sharing in smoking cessation $\mathrm{OHC}$

123<smiles>[CH]1CC1</smiles> 
INTR

32,7

124

\section{Methods}

\section{The questionnaire}

To investigate the determinants of knowledge sharing in smoking cessation OHCs, we employed an online survey for collecting data in Finland and China. The questionnaire was initially prepared in English and reviewed for content validity by two IS researchers. Then it was translated into Finnish by one author whose mother tongue is Finnish and into Chinese by another of the authors, who is a native speaker of Chinese. For reasons of translation quality, the questionnaire was further reviewed by an administrator of the Finnish smoking cessation OHC (Stumppi.fi), and additional checking for the Chinese-language questionnaire was performed by two Chinese IS researchers. With administrator assistance, 20 Stumppi.fi users were invited to participate in a pilot test of the Finnish-language online survey, on the basis of which the questionnaire was revised further. Questions were reordered to improve the flow and clarity of the questionnaire both in Chinese and in Finnish.

\section{Construct measurements}

The proposed research model contains six constructs: social ties, shared vision, shared language, reciprocity, commitment and knowledge sharing. The items for all the constructs in the model were measured via multiple-item scales with instrumentation adapted from items suggested in the literature. Further rewording was carried out in light of the context of smoking cessation $\mathrm{OHCs}$. The metrics for social ties, shared language and shared vision were based on contributions from (Chiu et al., 2006), while those for reciprocity were taken directly from work by Wasko and Faraj (2005). The commitment items were items suggested by (Liang et al., 2011) but in adapted form. Finally, knowledge sharing was measured via four items adapted from items in a study by (Hsu et al., 2007). A five-point Likert scale from "strongly disagree" (1) to "strongly agree" (5) was employed to measure all the items in the research model. The set of measurement items for all the constructs included is summarized by the list in Table A1.

\section{Data collection}

Individual users of smoking cessation OHCs were the respondents in our study. For this research, we selected two nonprofit smoking cessation $\mathrm{OHCs}$, the Finland-based Stumppi.fi and one accessed in China via a subbar in Baidu's "post" bar that is denoted as for smoking cessation. We recruited individual users of the OHCs to take part in the online survey published within the two OHCs. The first page of the questionnaire presented potential respondents with a consent form stressing the voluntary nature of participation and stating that respondents may withdraw from the survey at any time. Only those agreeing to participate in it after acknowledgment via the consent form proceeded to complete the survey. The questionnaire presented questions on the respondent's background, smoking history and opinions and perceptions related to knowledge sharing in smoking cessation OHCs. Each respondent completing the Finnish survey received a free electronic movie ticket as an incentive, and each completing the Chinese version received a red envelope containing a random amount of money from 1 $\mathrm{RMB}$ to $3 \mathrm{RMB}$. Before the collection of data, the ethics committee of the authors' home university granted approval for this study.

Sampling for the online survey began on November 13, 2018, in China and December 17, 2018, in Finland. In total, we received 235 response forms, from 48 individuals in Finland and 187 in China. After removal of responses that either did not demonstrate informed consent to participate in the survey ( 2 in Finland, 48 in China) or suggested unreliable answers - for example, from people completing the survey in a very short span of time (12 in China) - we had a valid sample of 173 response forms for data analysis. 
Roughly $59.5 \%$ of the respondents indicated that they were male, $37.0 \%$ specified that they were female and 3.5\% did not disclose their gender. Most were aged 25-67 (87.8\% fell within this range), and all had smoking cessation $\mathrm{OHC}$ use experience. They represented various stages of smoking cessation. Table 4 presents their demographic information and some characteristics of the respondents' smoking cessation $\mathrm{OHC}$ use.

\section{Assessment of common method bias and measurement invariance}

To check for the presence of common method bias in this study, we used both Harman's single-factor test (Podsakoff et al., 2003) and the unmeasured latent method construct (UMLC) test developed by Williams et al. (1989). Specifically, first, we subjected all the variables to factor analysis to test whether a single factor emerged, and no single component was found to account for more than $50 \%$ of the total variance explained. Second, the UMLC approach was assessed with three models: a method-only model, a trait-only model and a trait and method model. The results were listed as below:

(1) M1 was a method-only model in which all items were loaded on one factor (i.e. the method factor $)\left(x^{2}(90)=643.847, p=0.000, \mathrm{CFI}=0.680, \mathrm{TLI}=0.627, \operatorname{RMSEA}=0.189\right)$.

(2) M2 was a trait-only model in which items were loaded on its expected construct $\left(x^{2}(80)=210.078, p=0.000, \mathrm{CFI}=0.925, \mathrm{TLI}=0.901, \mathrm{RMSEA}=0.079\right)$.

(3) M3 was a trait and method model in which a common method factor linking to all items was added into M1 $\left(x^{2}(65)=131.902, p=0.000, \mathrm{CFI}=0.961\right.$, TLI $=0.938$, RMSEA $=0.077$ ).

Comparing these three models, $\mathrm{M} 2$ and $\mathrm{M} 3$ are much better than M1 according to the data, and M3 is only slightly better than M2. This indicates that trait rather than the common

\begin{tabular}{|c|c|c|c|}
\hline Measurement & Items & Count & Percentage $(\%)$ \\
\hline \multirow[t]{2}{*}{ Country } & Finland & 46 & 26.6 \\
\hline & China & 127 & 73.4 \\
\hline \multirow[t]{3}{*}{ Gender } & Male & 103 & 59.5 \\
\hline & Female & 64 & 37.0 \\
\hline & Unwilling to disclose & 6 & 3.5 \\
\hline \multirow{4}{*}{ Age } & $15-24$ years old & 17 & 9.8 \\
\hline & 25-44 years old & 117 & 67.6 \\
\hline & 45-65 years old & 35 & 20.2 \\
\hline & 65 years or older & 4 & 2.3 \\
\hline \multirow{5}{*}{ Frequency of visiting } & Less than once per week & 34 & 19.7 \\
\hline & Once a week & 27 & 15.6 \\
\hline & Several times per week but not every day & 70 & 40.5 \\
\hline & Once a day & 22 & 12.7 \\
\hline & Multiple times each day & 20 & 11.6 \\
\hline \multirow[t]{4}{*}{ Typical duration of a visit } & Less than $10 \mathrm{~min}$ & 25 & 14.5 \\
\hline & $10-30 \mathrm{~min}$ & 106 & 61.3 \\
\hline & $30-60 \mathrm{~min}$ & 38 & 22.0 \\
\hline & More than an hour & 4 & 2.3 \\
\hline \multirow[t]{6}{*}{ Stage in smoking cessation } & Precontemplation & 4 & 2.3 \\
\hline & Contemplation & 45 & 26.0 \\
\hline & Preparation & 19 & 11.0 \\
\hline & Action & 40 & 23.1 \\
\hline & Maintenance & 50 & 28.9 \\
\hline & Termination & 15 & 8.7 \\
\hline
\end{tabular}

Knowledge sharing in smoking cessation $\mathrm{OHC}$ 
INTR 32,7

\section{6}

method factor explains most of the variance (Williams et al., 1989). Therefore, common method bias is unlikely to be an issue in this study. Overall, there is strong support for concluding that common method bias is not a critical concern in the current study.

To assess whether differences exist between the respondents from China and Finland, we conducted an invariance test by applying the Measurement Invariance Assessment (MICOM) procedure proposed by (Henseler et al., 2016b). The results show all $c$ value, the difference of the mean value and the variance of composites between the two countries fall between the upper and lower bounds of the 95\% confidence interval as recommended by Henseler et al. (2016b); thus, the measurement invariance is established in this study.

\section{Data analysis}

We employed partial least squares (SmartPLS 3.0) to test the measurement model and structural model.

Testing of the measurement model. Testing the measurement model involved evaluating the items' convergent validity and discriminant validity. Convergent validity can be assessed via certain standard estimates: the factor loading of each measurement item on the respective constructs must be above 0.7 , each construct's composite reliability (CR) must be above the cutoff value of 0.8 , and the average variance extracted (AVE) by each construct must exceed 0.5 (Hulland, 1999; Tenenhaus et al., 2005). As Table 5 shows, the factor loadings of all measurement items encompassed by the research model exceed the prescribed threshold of 0.70, and the CR and AVE values for all constructs are above the 0.8 and 0.5 cutoffs, respectively, showing evidence of convergent validity.

To assess discriminant validity, we used two techniques, one developed by Fornell and Larcker (1981) and the other proposed by Henseler et al. (2015). Firstly, we compared the square root of the AVE for each construct against its correlation with other constructs. As Table 6 shows, each construct's AVE square root value is greater than the estimated correlation with any other constructs. Secondly, we conducted a comparison between items' loading for an associated construct and their cross-loading on other constructs. All items

\begin{tabular}{|c|c|c|c|c|c|}
\hline Construct & Item & Factor loading & Cronbach's alpha & $\mathrm{CR}$ & AVE \\
\hline \multirow[t]{4}{*}{ Knowledge sharing (KS) } & KS1 & 0.923 & \multirow[t]{4}{*}{0.935} & \multirow[t]{4}{*}{0.954} & \multirow[t]{4}{*}{0.838} \\
\hline & KS2 & 0.898 & & & \\
\hline & KS3 & 0.923 & & & \\
\hline & KS4 & 0.916 & & & \\
\hline \multirow[t]{3}{*}{ Commitment (CO) } & $\mathrm{CO} 1$ & 0.896 & \multirow[t]{3}{*}{0.844} & \multirow[t]{3}{*}{0.906} & \multirow[t]{3}{*}{0.763} \\
\hline & $\mathrm{CO} 2$ & 0.844 & & & \\
\hline & $\mathrm{CO} 3$ & 0.879 & & & \\
\hline \multirow{2}{*}{ Reciprocity (RE) } & RE1 & 0.867 & \multirow{2}{*}{0.704} & \multirow{2}{*}{0.871} & \multirow{2}{*}{0.771} \\
\hline & RE2 & 0.890 & & & \\
\hline \multirow[t]{4}{*}{ Shared language (SL) } & SL1 & 0.794 & \multirow[t]{4}{*}{0.775} & \multirow[t]{4}{*}{0.854} & \multirow[t]{4}{*}{0.595} \\
\hline & SL2 & 0.759 & & & \\
\hline & SL3 & 0.708 & & & \\
\hline & SL4 & 0.820 & & & \\
\hline \multirow{3}{*}{ Shared vision (SV) } & SV1 & 0.846 & \multirow{3}{*}{0.786} & \multirow{3}{*}{0.875} & \multirow[t]{3}{*}{0.700} \\
\hline & SV2 & 0.784 & & & \\
\hline & SV3 & 0.877 & & & \\
\hline \multirow[t]{4}{*}{ Social ties (ST) } & ST1 & 0.954 & \multirow[t]{4}{*}{0.952} & \multirow[t]{4}{*}{0.965} & \multirow[t]{4}{*}{0.875} \\
\hline & ST2 & 0.909 & & & \\
\hline & ST3 & 0.935 & & & \\
\hline & ST4 & 0.942 & & & \\
\hline
\end{tabular}

Table 5.

Results of confirmatory factor analysis 
loaded on their corresponding construct more strongly than on other constructs (figures are presented in Table 7). Finally, we applied a new approach, the heterotrait-monotrait (HTMT) ratio of correlations suggested by Henseler et al. (2015), to assess the discriminant validity in variance-based structural equation modeling (SEM). An HTMT of 0.90 has been posited to be an acceptable upper limit (Henseler et al., 2015), and all HTMT values we obtained are below 0.90 (see Table 8), which indicates that discriminant validity has been established. Overall,
Knowledge
sharing in
smoking
cessation OHC

127

\begin{tabular}{lcccccr}
\hline & KS & CO & RE & SL & SV & ST \\
\hline Knowledge sharing (KS) & 0.915 & & & & & \\
Commitment (CO) & 0.694 & 0.873 & & & & \\
Reciprocity (RE) & 0.477 & 0.448 & 0.878 & & & \\
Shared language (SL) & 0.518 & 0.552 & 0.432 & 0.771 & & \\
Shared vision (SV) & 0.489 & 0.588 & 0.501 & 0.686 & 0.837 & 0.935 \\
Social ties (ST) & 0.813 & 0.674 & 0.383 & 0.527 & 0.417
\end{tabular}

Note(s): The diagonal elements represent square root of average variance extracted (AVE)

Table 6.

Correlations and square roots of $\mathrm{AVE}$

\begin{tabular}{lcccccc}
\hline & KS & CO & RE & SL & SV & ST \\
\hline KS1 & 0.923 & 0.648 & 0.472 & 0.476 & 0.495 & 0.720 \\
KS2 & 0.898 & 0.558 & 0.415 & 0.504 & 0.413 & 0.713 \\
KS3 & 0.923 & 0.651 & 0.468 & 0.447 & 0.424 & 0.756 \\
KS4 & 0.916 & 0.676 & 0.393 & 0.472 & 0.458 & 0.783 \\
CO1 & 0.637 & 0.896 & 0.362 & 0.457 & 0.518 & 0.606 \\
CO2 & 0.602 & 0.844 & 0.394 & 0.484 & 0.520 & 0.592 \\
CO3 & 0.575 & 0.879 & 0.421 & 0.508 & 0.503 & 0.564 \\
RE1 & 0.400 & 0.369 & 0.867 & 0.33 & 0.370 & 0.326 \\
RE2 & 0.437 & 0.416 & 0.890 & 0.426 & 0.504 & 0.346 \\
SL1 & 0.374 & 0.404 & 0.343 & 0.794 & 0.454 & 0.419 \\
SL2 & 0.358 & 0.368 & 0.362 & 0.759 & 0.615 & 0.317 \\
SL3 & 0.332 & 0.385 & 0.413 & 0.708 & 0.566 & 0.370 \\
SL4 & 0.501 & 0.519 & 0.260 & 0.820 & 0.509 & 0.494 \\
SV1 & 0.378 & 0.538 & 0.454 & 0.514 & 0.846 & 0.319 \\
SV2 & 0.379 & 0.405 & 0.376 & 0.545 & 0.784 & 0.292 \\
SV3 & 0.463 & 0.529 & 0.429 & 0.650 & 0.877 & 0.423 \\
ST1 & 0.761 & 0.612 & 0.354 & 0.502 & 0.396 & 0.954 \\
ST2 & 0.753 & 0.629 & 0.320 & 0.496 & 0.410 & 0.909 \\
ST3 & 0.743 & 0.625 & 0.382 & 0.506 & 0.332 & 0.935 \\
ST4 & 0.783 & 0.653 & 0.376 & 0.469 & 0.422 & 0.942 \\
Note(s) &. & & & & & \\
\end{tabular}

Note(s): KS, knowledge sharing; CO, commitment; RE, reciprocity; SL, shared language; SV, shared vision; ST, social ties)

Table 7.

Loadings and crossloadings

\begin{tabular}{|c|c|c|c|c|c|c|}
\hline & KS & $\mathrm{CO}$ & $\mathrm{RE}$ & SL & SV & \\
\hline \multicolumn{7}{|l|}{ Knowledge sharing (KS) } \\
\hline Commitment (CO) & 0.778 & & & & & \\
\hline Reciprocity (RE) & 0.588 & 0.581 & & & & \\
\hline Shared language (SL) & 0.595 & 0.672 & 0.600 & & & Table 8. \\
\hline Shared vision (SV) & 0.566 & 0.720 & 0.670 & 0.883 & & Heterotrait-monotrait \\
\hline Social ties (ST) & 0.860 & 0.750 & 0.467 & 0.602 & 0.476 & ratios of correlations \\
\hline
\end{tabular}


INTR 32,7

128 there is strong empirical support for concluding that discriminant validity exists for all constructs in our theoretical model.

The multicollinearity of each construct was also examined by assessing the values of variance inflation factor (VIF) (Kock and Lynn, 2012). As shown in Table 9, the VIF values in this study were all lower than the suggested threshold of 3.3 (Kock and Lynn, 2012). Thus, multicollinearity was not a critical issue in this study.

Testing of the structural model. A PLS bootstrapping procedure was applied in the structural model test, including the path significance of the hypothesized effect and the explanatory power of the model, via SEM techniques. As postulated, social ties $(\beta=0.522$, $p<0.001)$ and reciprocity $(\beta=0.124, p<0.05)$ showed significant positive effects on knowledge sharing, thus supporting $\mathrm{H} 1$ and $\mathrm{H} 4$. Contrary to expectations, shared vision, shared language and commitment displayed no significant influence on knowledge sharing. Accordingly, $\mathrm{H} 2$, $\mathrm{H} 3$ and $\mathrm{H} 4$ were not supported. Our model explains $74.5 \%$ of the variance in knowledge sharing in smoking cessation $\mathrm{OHCs}$, indicating that it has good explanatory power (see Figure 2). The results of the control variable test indicate that gender $(\beta=-0.077$, $p<0.05)$ and country $(\beta=0.159, p<0.05)$ affect knowledge sharing in smoking cessation OHCs significantly while age does not.
Table 9.

Full collinearity test for VIF values

\begin{tabular}{lc}
\hline Construct & VIF value \\
\hline Knowledge sharing (KS) & 1.393 \\
Commitment (CO) & 1.521 \\
Reciprocity (RE) & 1.219 \\
Shared language (SL) & 1.573 \\
Shared vision (SV) & 1.429 \\
Social ties (ST) & 2.010 \\
\hline
\end{tabular}

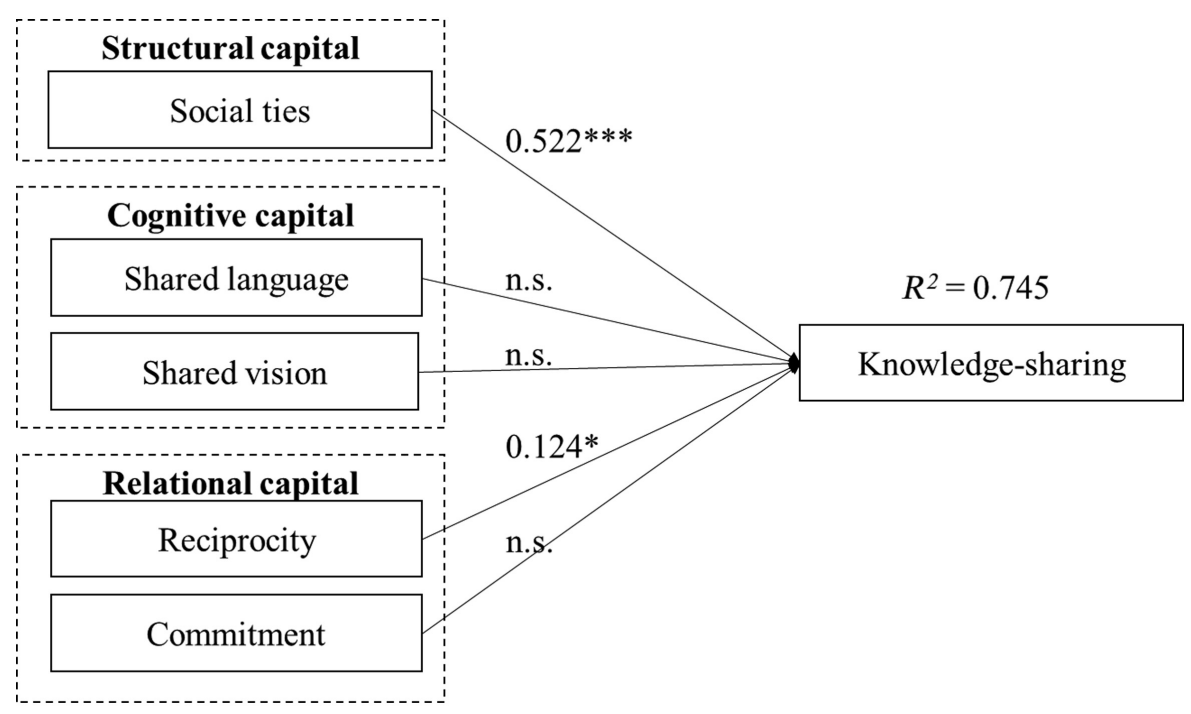

Figure 2.

The structural model 
We examined the predictive validity of the model by computing Stone-Geisser's $Q^{2}$ (Geisser, 1974; Hair et al., 2017; Stone, 1974), which is measured via the blindfolding technique of SmartPLS 3.0. Our $Q^{2}$ for knowledge sharing is 0.573 , indicating good predictive relevance.

Finally, the goodness of fit was tested by the measurement of the standardized root mean square residual (SRMR) (Henseler et al., 2016a). The resulting SRMR value, 0.060, is lower than the acceptability maximum of 0.08 proposed by Hu and Bentler (1999). Therefore, our model shows an acceptable fit.

Moderator analysis. Finally, we tested the moderation effects of the user's stage in quitting to see whether the strength of the relationships between the proposed antecedents (social ties, shared language, shared vision, reciprocity and commitment) and knowledge sharing varies with the smoking cessation stage of individual users of smoking cessation OHCs. We divided the users into three subgroups on the basis of broad stages in ceasing smoking: those intending to quit but not taking action, including users in the contemplation or preparation stage (Group A); those in the action stage (Group B); and those who had succeeded in having not smoked for at least six months, including people in the maintenance or temptation stage (Group C). Note that the four responses of users in the precontemplation stage, without an intention to quit smoking, were excluded. We applied multigroup analysis (MGA) (Henseler, 2012) with SmartPLS 3.0 in the moderatingeffect test.

Prior to the MGA, we used MICOM procedure proposed by Henseler et al. (2016b) to assess whether differences existed among three groups. Since there are three groups in this study, every two groups were analyzed at a time. Overall, the analysis was carried out three times (i.e. Group A vs Group B; Group A vs Group C; Group B vs Group C). The results show that all $c$ values met the criteria suggested by Henseler $e$ t al. (2016b), but the difference of the mean value and the variance of composites for several constructs did not fall between the upper and lower bounds of the 95\% confidence interval. Thus, partial measurement invariance is established, which permits MGA in this study (Henseler et al., 2016b).

The MGA results are presented in Table 10. Social ties and commitment emerged as significant determinants of knowledge sharing among Group A users, who intended to quit smoking but had not yet taken action. Commitment is the only factor exerting a positive influence on knowledge sharing among those in Group B, who were actively trying to quit smoking. For those in Group C, who had successfully abstained for at least six months, social ties and shared vision were found to be significant predictors of knowledge sharing in the smoking cessation OHCs.

Social ties exhibited a stronger significant influence on knowledge sharing among those who had not smoked for at least six months (Group C) than on those who only intended to quit

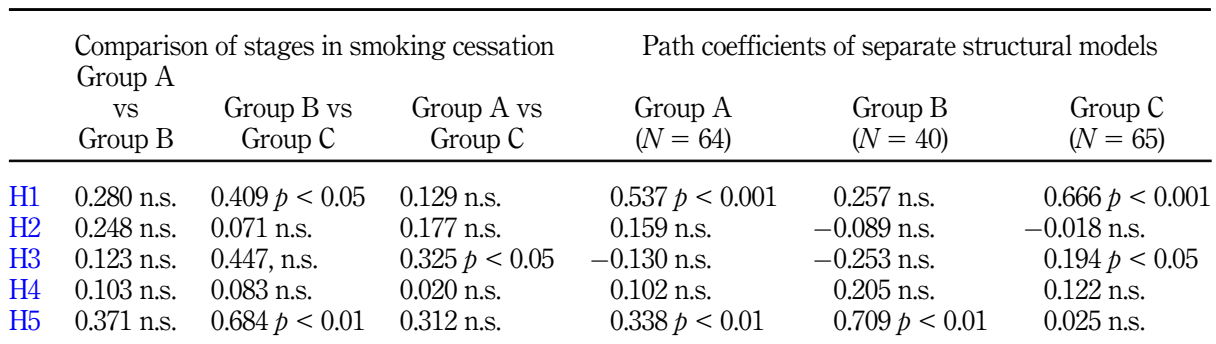

Note(s): Group A, users who intend to quit but have not taken action; Group B, users who are in the action stage; Group C, users who have succeeded in having not smoked for at least six months; n.s., not significant
Knowledge sharing in smoking cessation OHC

129

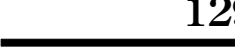

(1)


INTR 32,7

130

smoking (Group A), but no significant influence on those actively attempting to quit (Group B) was found. A significant difference was revealed only between groups B and C. Shared vision showed a significant impact on knowledge sharing among users who had not smoked for at least six months but not on the other two groups' knowledge sharing. A significant difference was found between Group A and Group C. For commitment, a stronger significant influence on knowledge sharing was visible among those actively attempting to quit smoking than among those with only an intent to cease, and no significant influence was visible for those who had abstained from smoking for at least six months. A significant difference was found between groups $\mathrm{B}$ and $\mathrm{C}$ in this regard. Finally, neither shared language nor reciprocity was a significant factor predicting knowledge sharing, with no significant difference evident among the groups. Thus, H6a, H6c and H6e were supported, whereas H6b and H6d were not.

\section{Discussion}

Of the several social-capital-related factors we investigated that might affect knowledge sharing in smoking cessation $\mathrm{OHCs}$, the results show that two dimensions of social capital have significant impacts on users' knowledge sharing in these OHCs: structural capital (social ties) and relational capital (reciprocity). The results also offer evidence for the existence of a moderating effect of one's stage in smoking cessation on the relationships between the antecedents and knowledge sharing.

Structural capital (social ties) was found to be the most important factor in knowledge sharing in smoking cessation OHCs. This finding is consistent with research regarding knowledge sharing among bloggers (Chai et al., 2011) and users of OHCs (Zhao et al., 2016). Prior research shows that social ties motivate knowledge sharing behavior among bloggers and support $\mathrm{OHC}$ users' combination and externalization in knowledge creation. In the study Chen and Shi (2015) conducted on special-interest OHCs - focused on HIV - users with stronger online social ties appeared more likely to share information/knowledge than those with weaker social ties. In smoking cessation OHCs, users establish social ties with other users via social interactions. Such ties may get strengthened over time, in line with the frequency and duration of interactions (Chai et al., 2011); for instance, users might build friendships in OHCs. Such friendships, in turn, create peer pressure among users to share more knowledge with their online friends or other contacts (Chai et al., 2011). For instance, they might disseminate more knowledge in the communities to support other smokers' efforts to quit, whether sharing their own stories, providing tips or commenting on posts by other members of the online community.

Our finding that reciprocity is another important factor predicting knowledge sharing in smoking cessation OHCs is consistent with the research results of (Chai et al., 2011) and of Chang and Chuang (2011). The literature attests that norms of reciprocity have a positive effect on knowledge sharing in blogs (Chai et al., 2011) and on both the quantity and quality of knowledge sharing in online communities more broadly (Chang and Chuang, 2011). In their research on HIV-related OHCs, Chen and Shi (2015) found reciprocity to correlate positively with information sharing. Likewise, when users of smoking cessation OHCs believe that others care about their contributions and are going to respond to them with similar offerings, they will share more knowledge in the communities to support others.

Contrary to our hypothesis, commitment did not appear to exert a significant influence on knowledge sharing in smoking cessation OHCs. This finding is at odds with those of Yu et al. (2013) and of Wiertz and de Ruyter (2007). In their research on knowledge-intensive work teams, Yu et al. (2013) found that commitment positively affects sharing both explicit and tacit knowledge at the level of individuals. The research results of Wiertz and de Ruyter (2007) in commercial online communities likewise indicate that commitment to online communities affects the quantity and quality of knowledge sharing significantly. One 
possible reason is that users of smoking cessation OHCs keep anonymous online and do not know each other, and their commitment to the OHCs might be weaker than intensive networks. Prior research has found that anonymity weakens users' group identification toward online communities (Kim et al., 2019). In addition, unlike professional or customeroriented online communities, users of smoking cessation $\mathrm{OHCs}$ often experience a sense of urgency about obtaining social support to cope with difficult situations caused by smoking cessation. Thus, they tend to use smoking cessation OHCs intermittently and irregularly, and their commitment to smoking cessation OHCs might also be weaker than other online communities.

Our finding that cognitive capital, including shared language and shared vision, has no significant impact on knowledge sharing in smoking cessation OHCs is part of a complex picture. While this result is at odds with some previous findings on the impact of cognitive capital on knowledge sharing in various online communities, such as IT-oriented online communities (Chiu et al., 2006) and general OHCs (Zhou, 2019), it supports the conclusion of Zhao et al. (2016) offered for specialized OHCs. In professional online communities, expertise and common language in a professional domain and shared values and goals about collective actions are important for users to avoid misunderstanding and improve communication efficiency. Quitting smoking is a well-known topic, and many individuals (even some nonsmokers) are familiar with some terminologies or jargons regarding smoking cessation. When users join in smoking cessation OHCs, they have the general common goal of stopping tobacco use. Users of smoking cessation $\mathrm{OHCs}$ might have already established the shared language and shared vision when engaging in smoking cessation OHCs. In addition, the inconsistent findings between prior studies on $\mathrm{OHCs}$ indicate that we should be cautious about the research context when studying the impacts of cognitive capital on knowledge sharing in OHCs. Compared with general OHCs, the number of users of smoking cessation $\mathrm{OHCs}$ is much smaller, and the level of homophily is higher. To cope with the difficulties caused by the same health concern, forming robust relationships among users in these OHCs might be necessary for motivating knowledge sharing activities rather than developing a shared language or vision (Zhao et al., 2016).

The moderating effect of the smoking cessation stage on the relationships between some of the proposed antecedents and knowledge sharing is one of the most valuable contributions of the study. A moderating effect was visible on the paths from social ties, shared vision and commitment to knowledge sharing but not between other posited antecedents (shared language and reciprocity) and knowledge sharing. This might be due to stage-specific differences in both needs and the user's purposes behind using smoking cessation OHCs.

\section{Conclusion}

The study contributes to research and practice with regard to individual-level knowledge sharing in smoking cessation OHCs on several fronts.

\section{Contributions to theory}

This study enriches the knowledge sharing literature by unpacking the context of smoking cessation OHCs and clarifying the role of social capital for knowledge sharing in the specific context of smoking cessation OHCs. The literature has largely ignored the knowledgesharing behavior in such OHCs. Investigating knowledge sharing in this specific OHC context from the standpoint of social capital, our work addresses this gap and answers the call from Sergeeva and Andreeva (2016) to bring context back into knowledge sharing research.
Knowledge sharing in smoking cessation $\mathrm{OHC}$ 
INTR 32,7

132

Secondly, the theoretical angle of social capital yields insights into the mechanisms underlying knowledge sharing in smoking cessation OHCs. Our findings show that structural capital and relational capital built in smoking cessation OHCs can motivate users' knowledge sharing in these OHCs. The social-capital-related mechanisms identified speak to the potential value of enhancing the social relationships in the networks within smoking cessation $\mathrm{OHCs}$ in pursuit of stronger knowledge sharing. The insignificant impact of cognitive capital (i.e. shared vision and language) on knowledge sharing in smoking cessation OHCs indicates that though social capital theory can help explain knowledge sharing in online communities, it is necessary to consider the research context when applying social capital theory in knowledge sharing research as the roles of different social factors might vary in explaining knowledge sharing in different contexts.

Thirdly, investigating the components that construct social capital helps one understand the dimensions of social capital - in our case, those specific to smoking cessation online communities. This research disentangled the components of the three dimensions of social capital: structural capital (social ties), cognitive capital (shared language and vision) and relational capital (reciprocity and commitment). Specifically, our empirical evidence of positive effects of structural capital (social ties) and relational capital (reciprocity) on knowledge sharing in smoking cessation OHCs provides further support for concluding that structural and relational capital can facilitate users' knowledge sharing behavior in an online environment (Chiu et al., 2006; Wasko and Faraj, 2005). The findings also inform the literature on smoking cessation OHCs with new insights that may assist in optimizing the mechanisms of users' knowledge sharing behavior in light of the structural capital and relational capital built in smoking cessation OHCs.

The findings connected with the smoking cessation stage's moderating influence constitute a fourth contribution: they provide evidence that user context is a critical factor for explaining how social capital affects knowledge sharing in smoking cessation OHCs. This represents new insight for a greater understanding of knowledge sharing in these OHCs among different user groups.

\section{Practical significance}

The results offer insights through which practitioners can better promote knowledge sharing activities in smoking cessation OHCs. Firstly, these findings from the social capital perspective indicate that it is critical for those managing smoking cessation OHCs to exploit the power of social capital in these online communities in pursuit of enhanced knowledge sharing, through such means as employing strategies to help users with social-bond development and to encourage reciprocal activities in the $\mathrm{OHC}$.

Secondly, this work highlights the salient role of social ties in determining knowledge sharing. Accordingly, those who run smoking cessation OHCs should develop strategies and mechanisms to enhance relationship development on users' part, so as to promote knowledge sharing in smoking cessation OHCs. For instance, the administrators could arrange smokingcessation-related online social events or campaigns associated with the $\mathrm{OHC}$ to help the users interact with each other. This would promote the formation of new social ties and sustain existing online relationships in these communities, thereby potentially enhancing knowledge sharing in them. The managers of smoking cessation OHCs could also invite smoking cessation experts to join in their smoking cessation $\mathrm{OHC}$, not only to provide professional knowledge but also to facilitate interaction among the members of the community. That may nurture the development of social ties among users too.

A third relevant contribution is the finding of a positive effect of reciprocity on knowledge sharing. In response, managers should develop approaches that boost the reciprocity in smoking cessation $\mathrm{OHCs}$ - for instance, adding functions that allow users to reward 
knowledge contributors or respond to others' postings conveniently. In addition, those managing smoking cessation OHCs should motivate members of the OHCs to support their peers by sharing information and knowledge, through invitations to establish a dedicated discussion forum or thread. Doing this should increase the likelihood of other users contributing actively to the $\mathrm{OHCs}$, on account of reciprocity considerations (related to knowledge sharing, etc.).

Fourthly, because we found the user's stage in smoking cessation to moderate relationships between social capital and knowledge sharing, managers should consider user context, such as the needs and goals of users at various stages on the journey of quitting. For instance, smoking cessation OHC service providers could offer custom content that is based on users' stage of ceasing smoking to meet their personal needs. This may help with knowledge sharing in the communities.

While offering insights that inform scholars' and practitioners' understanding of knowledge sharing in smoking cessation OHCs, this study has certain limitations. Firstly, because of the limits inherent to online surveys, the data we collected may not add in-depth information for explaining the nuanced features of social capital with regard to sharing knowledge in smoking cessation OHCs. Therefore, further methods could be employed to enrich the findings in this special domain. For instance, one could combine quantitative and qualitative research. Secondly, the five social capital factors proposed in our research model may not fully capture social capital's effects on knowledge sharing in these OHCs. Other facets of each dimension (e.g. trust on the relational dimension) that may be connected with knowledge sharing in smoking cessation $\mathrm{OHCs}$ could be taken into consideration in future research. Another possible avenue for further research would be to examine the moderating effects of other noteworthy elements, such as socioeconomic status, which has been found to be closely connected with smoking (Laaksonen et al., 2005). Finally, researchers could consider collecting data from OHCs focusing on different health concerns (e.g. alcohol and drug addiction) and various countries to generalize our findings to addiction cessation $\mathrm{OHCs}$.

\section{References}

Adler, P.S. and Kwon, S.W. (2002), "Social capital: prospects for a new concept", Academy of Management Review, Vol. 27 No. 1, pp. 17-40.

Alexander, J.P., Coleman, B.N., Johnson, S.E., Tessman, G.K., Tworek, C. and Dickinson, D.M. (2016), "Smoke and vapor: exploring the terminology landscape among electronic cigarette users", Tobacco Regulatory Science, Vol. 2 No. 3, pp. 204-213.

Bartelt, V.L., Urbaczewski, A., Mueller, A.G. and Sarker, S. (2020), "Enabling collaboration and innovation in Denver's smart city through a living lab: a social capital perspective", European Journal of Information Systems, Vol. 29 No. 4, pp. 369-387.

Brown-Johnson, C.G. and Popova, L. (2016), "Exploring smoking stigma, alternative tobacco product use, and quit attempts", Health Behavior and Policy Review, Vol. 3 No. 1, pp. 13-20.

Cabrera, E.F. and Cabrera, A. (2005), "Fostering knowledge sharing through people management practices", International Journal of Human Resource Management, Vol. 16 No. 5, pp. 720-735.

Castaldelli-Maia, J.M., Ventriglio, A. and Bhugra, D. (2016), “Tobacco smoking: from 'glamour' to 'stigma'. A comprehensive review”, Psychiatry and Clinical Neurosciences, Vol. 70 No. 1, pp. 24-33.

Chai, S., Das, S. and Rao, H.R. (2011), "Factors affecting bloggers' knowledge sharing: an investigation across gender", Journal of Management Information Systems, Vol. 28 No. 3, pp. 309-341.

Chang, H.H. and Chuang, S.S. (2011), "Social capital and individual motivations on knowledge sharing: participant involvement as a moderator", Information and Management, Vol. 48 No. 1, pp. 9-18.
Knowledge sharing in smoking cessation $\mathrm{OHC}$ 
INTR 32,7

Chang, C.W., Huang, H.C., Chiang, C.Y., Hsu, C.P. and Chang, C.C. (2012), "Social capital and knowledge sharing: effects on patient safety", Journal of Advanced Nursing, Vol. 68 No. 8, pp. 1793-1803.

Chen, L. and Shi, J. (2015), "Social support exchanges in a social media community for people living with HIV/AIDS in China", AIDS Care, Vol. 27 No. 6, pp. 693-696.

Cheung, Y.T.D., Chan, C.H.H., Wang, M.P., Li, H.C.W. and Lam, T.H. (2017), "Online social support for the prevention of smoking relapse: a content analysis of the WhatsApp and Facebook social groups", Telemedicine Journal and e-Health, Vol. 23 No. 6, pp. 507-516.

Cheung, Y.T., Chan, C.H., Lai, C.K., Chan, W.F., Wang, M.P., Li, H.C., Chan, S.S. and Lam, T.H. (2015), "Using WhatsApp and Facebook online social groups for smoking relapse prevention for recent quitters: a pilot pragmatic cluster randomized controlled trial”, Journal of Medical Internet Research, Vol. 17 No. 10, pp. 1-15.

Chiu, C.M., Hsu, M.H. and Wang, E.T.G. (2006), "Understanding knowledge sharing in virtual communities: an integration of social capital and social cognitive theories", Decision Support Systems, Vol. 42 No. 3, pp. 1872-1888.

Choi, Y. (2015), "The impact of social capital on employees' knowledge sharing behavior: an empirical analysis of U.S. Federal agencies", Public Performance and Management Review, Vol. 39 No. 2, pp. 381-405.

Chow, W.S. and Chan, L.S. (2008), "Social network, social trust and shared goals in organizational knowledge sharing", Information and Management, Vol. 45 No. 7, pp. 458-465.

Cobb, N.K., Graham, A.L. and Abrams, D.B. (2010), "Social network structure of a large online community for smoking cessation", American Journal of Public Health, Vol. 100 No. 7, pp. 1282-1289.

Ellison, N., Steinfield, C. and Lampe, C. (2006), "Spatially bounded online social networks and social capital", International Communication Association, Vol. 36, pp. 1-37.

Fornell, C. and Larcker, D.F. (1981), "Structural equation models with unobservable variables and measurement error - algebra and statistics", Journal of Marketing Research, Vol. 18 No. 3, pp. 382-388.

Geisser, S. (1974), “A predictive approach to the random effect model”, Biometrika, Vol. 61 No. 1, pp. 101-107.

Graham, A.L. and Amato, M.S. (2019), “Twelve million smokers look online for smoking cessation help annually: health information national trends survey data, 2005-2017”, Nicotine and Tobacco Research, Vol. 21 No. 2, pp. 249-252.

Graham, A.L., Papandonatos, G.D., Erar, B. and Stanton, C.A. (2015), "Use of an online smoking cessation community promotes abstinence: results of propensity score weighting", Health Psychology, Vol. 34S, pp. 1286-1295.

Granado-Font, E., Ferre-Grau, C., Rey-Renones, C., Pons-Vigues, M., Pujol Ribera, E., Berenguera, A., Barrera-Uriarte, M.L., Basora, J., Valverde-Trillo, A., Duch, J. and Flores-Mateo, G. (2018), "Coping strategies and social support in a mobile phone chat app designed to support smoking cessation: qualitative analysis", JMIR mHealth and uHealth, Vol. 6 No. 12 , pp. 1-12.

Hair, J.F. Jr, Hult, G.T.M., Ringle, C. and Sarstedt, M. (2017), A Primer on Partial Least Squares Structural Equation Modeling (PLS-SEM), 2nd ed., Sage, Thousand Oaks.

Hau, Y.S. and Kim, Y.-G. (2011), "Why would online gamers share their innovation-conducive knowledge in the online game user community? Integrating individual motivations and social capital perspectives", Computers in Human Behavior, Vol. 27 No. 2, pp. 956-970.

Hau, Y.S., Kim, B., Lee, H. and Kim, Y.-G. (2013), "The effects of individual motivations and social capital on employees' tacit and explicit knowledge sharing intentions", International Journal of Information Management, Vol. 33 No. 2, pp. 356-366. 
Hefler, M., Kerrigan, V., Freeman, B., Boot, G.R. and Thomas, D.P. (2019), "Using Facebook to reduce smoking among Australian aboriginal and Torres Strait Islander people: a participatory grounded action study", BMC Public Health, Vol. 19 No. 1, p. 615.

Henseler, J. (2012), "PLS-MGA: a non-parametric approach to partial least squares-based multi-group analysis", Challenges at the Interface of Data Analysis, Computer Science, and Optimization, Springer, pp. 495-501.

Henseler, J., Ringle, C.M. and Sarstedt, M. (2015), "A new criterion for assessing discriminant validity in variance-based structural equation modeling", Journal of the Academy of Marketing Science, Vol. 43 No. 1, pp. 115-135.

Henseler, J., Hubona, G. and Ray, P.A. (2016a), "Using PLS path modeling in new technology research: updated guidelines", Industrial Management \& Data Systems, Vol. 116 No. 1, pp. 2-20.

Henseler, J., Ringle, C.M. and Sarstedt, M. (2016b), "Testing measurement invariance of composites using partial least squares”, International Marketing Review, Vol. 33 No. 3, pp. 405-431.

Hsu, M.H., Ju, T.L., Yen, C.H. and Chang, C.M. (2007), "Knowledge sharing behavior in virtual communities: the relationship between trust, self-efficacy, and outcome expectations", International Journal of Human-Computer Studies, Vol. 65 No. 2, pp. 153-169.

Hu, L.T. and Bentler, P.M. (1999), "Cutoff criteria for fit indexes in covariance structure analysis: conventional criteria versus new alternatives", Structural equation Modeling: A Multidisciplinary Journal, Vol. 6 No. 1, pp. 1-55.

Hulland, J. (1999), "Use of partial least squares (PLS) in strategic management research: a review of four recent studies", Strategic Management Journal, Vol. 20 No. 2, pp. 195-204.

Kim, K.K., Lee, A.R. and Lee, U.-K. (2019), "Impact of anonymity on roles of personal and group identities in online communities", Information and Management, Vol. 56 No. 1, pp. 109-121.

Kock, N. and Lynn, G.S. (2012), "Lateral collinearity and misleading results in variance-based sem: an illustration and recommendations", Journal of the Association for Information Systems, Vol. 13 No. 7, pp. 546-580.

Laaksonen, M., Rahkonen, O., Karvonen, S. and Lahelma, E. (2005), "Socioeconomic status and smoking: analysing inequalities with multiple indicators", European Journal of Public Health, Vol. 15 No. 3, pp. 262-269.

Lakon, C.M., Pechmann, C., Wang, C., Pan, L., Delucchi, K. and Prochaska, J.J. (2016), "Mapping engagement in twitter-based support networks for adult smoking cessation", American Journal of Public Health, Vol. 106 No. 8, pp. 1374-1380.

Leana, C.R. and Van Buren, H.J. (1999), "Organizational social capital and employment practices", Academy of Management Review, Vol. 24 No. 3, pp. 538-555.

Li, C. (2020), "Comprehending user satisfaction with smoking-cessation online health communities: a social support perspective", in Cacace, M., Halonen, R., Li, H., Orrensalo, T.P., Li, C., Widén, G. and Suomi, R. (Eds), Well-Being in the Information Society. Fruits of Respect, Springer, Turku, pp. 112-127.

Li, C., Li, H. and Suomi, R. (2019), "Knowledge sharing in a smoking cessation online community: a privacy calculus perspective", 27th European Conference on Information Systems, Stockholm and Uppsala, Sweden, Association for Information Systems, pp. 1-13.

Li, C., Li, H. and Suomi, R. (2021), "Antecedents and consequences of the perceived usefulness of smoking cessation online health communities", Internet Research, Vol. ahead-of-print No. aheadof-print, doi: 10.1108/INTR-04-2020-0220.

Liang, T.P., Ho, Y.T., Li, Y.W. and Turban, E. (2011), "What drives social commerce: the role of social support and relationship quality", International Journal of Electronic Commerce, Vol. 16 No. 2, pp. $69-90$. 
INTR 32,7

Lu, Y. and Yang, D. (2011), "Information exchange in virtual communities under extreme disaster conditions", Decision Support Systems, Vol. 50 No. 2, pp. 529-538.

Maseeh, A. and Kwatra, G. (2005), "A review of smoking cessation interventions", MedGenMed: Medscape General Medicine, Vol. 7 No. 2, p. 24.

Messer, K., Trinidad, D.R., Al-Delaimy, W.K. and Pierce, J.P. (2008), "Smoking cessation rates in the United States: a comparison of young adult and older smokers", American Journal of Public Health, Vol. 98 No. 2, pp. 317-322.

Mojdeh, S., Head, M. and El Shamy, N. (2018), "Knowledge sharing in social networking sites: how context impacts individuals' social and intrinsic motivation to contribute in online communities", AIS Transactions on Human-Computer Interaction, Vol. 10 No. 2, pp. 82-104.

Mpinganjira, M. (2018), "Precursors of trust in virtual health communities: a hierarchical investigation", Information and Management, Vol. 55 No. 6, pp. 686-694.

Myneni, S., Fujimoto, K., Cobb, N. and Cohen, T. (2015), "Content-driven analysis of an online community for smoking cessation: integration of qualitative techniques, automated text analysis, and affiliation networks", American Journal of Public Health, Vol. 105 No. 6, pp. 1206-1212.

Myneni, S., Cobb, N. and Cohen, T. (2016), "In pursuit of theoretical ground in behavior change support systems: analysis of peer-to-peer communication in a health-related online community", Journal of Medical Internet Research, Vol. 18 No. 2, pp. 1-21.

Nahapiet, J. and Ghoshal, S. (1998), "Social capital, intellectual capital, and the organizational advantage", Academy of Management Review, Vol. 23 No. 2, pp. 242-266.

Nov, O., Ye, C. and Kumar, N. (2012), "A social capital perspective on meta-knowledge contribution and social computing", Decision Support Systems, Vol. 53 No. 1, pp. 118-126.

Pizacani, B.A., Martin, D.P., Stark, M.J., Koepsell, T.D., Thompson, B. and Diehr, P. (2008), "Longitudinal study of household smoking ban adoption among households with at least one smoker: associated factors, barriers, and smoker support”, Nicotine \& Tobacco Research, Vol. 10 No. 3, pp. 533-540.

Ploderer, B., Smith, W., Howard, S., Pearce, J. and Borland, R. (2013), "Patterns of support in an online community for smoking cessation”, in Prinz, W., Satchell, C., Koch, M. and Schlichter, J. (Eds), Proceedings of the 6th International Conference on Communities and Technologies, Munich, Germany, Association for Computing Machinery (ACM), New York, NY, pp. 26-35.

Podsakoff, P.M., MacKenzie, S.B., Lee, J.Y. and Podsakoff, N.P. (2003), "Common method biases in behavioral research: a critical review of the literature and recommended remedies", Journal of Applied Psychology, Vol. 88 No. 5, pp. 879-903.

Prochaska, J.O. and Velicer, W.F. (1997), "The transtheoretical model of health behavior change", American Journal of Health Promotion, Vol. 12 No. 1, pp. 38-48.

Prochaska, J.O., Velicer, W.F., Prochaska, J.M. and Johnson, J.L. (2004), "Size, consistency, and stability of stage effects for smoking cessation”, Addictive Behaviors, Vol. 29 No. 1, pp. 207-213.

Ray, S., Kim, S.S. and Morris, J.G. (2014), "The central role of engagement in online communities", Information Systems Research, Vol. 25 No. 3, pp. 528-546.

Rocheleau, M., Sadasivam, R.S., Baquis, K., Stahl, H., Kinney, R.L., Pagoto, S.L. and Houston, T.K. (2015), "An observational study of social and emotional support in smoking cessation twitter accounts: content analysis of tweets”, Journal of Medical Internet Research, Vol. 17 No. 1, p. e18.

Sergeeva, A. and Andreeva, T. (2016), "Knowledge sharing research: bringing context back in", Journal of Management Inquiry, Vol. 25 No. 3, pp. 240-261.

Stone, M. (1974), "Cross-validatory choice and assessment of statistical predictions", Journal of the Royal Statistical Society: Series B (Methodological), Vol. 36 No. 2, pp. 111-133.

Stuber, J. and Galea, S. (2009), "Who conceals their smoking status from their health care provider?", Nicotine and Tobacco Research, Vol. 11 No. 3, pp. 303-307. 
Tenenhaus, M., Vinzi, V.E., Chatelin, Y.-M. and Lauro, C. (2005), "PLS path modeling”, Computational Statistics and Data Analysis, Vol. 48 No. 1, pp. 159-205.

Thrul, J., Klein, A.B. and Ramo, D.E. (2015), "Smoking cessation intervention on Facebook: which content generates the best engagement?", Journal of Medical Internet Research, Vol. 17 No. 11, pp. 1-11.

Tsai, W.P. and Ghoshal, S. (1998), "Social capital and value creation: the role of intrafirm networks", Academy of Management Journal, Vol. 41 No. 4, pp. 464-476.

van der Tempel, J., Noormohamed, A., Schwartz, R., Norman, C., Malas, M. and Zawertailo, L. (2016), "Vape, quit, tweet? Electronic cigarettes and smoking cessation on Twitter", International Journal of Public Health, Vol. 61 No. 2, pp. 249-256.

Wakefield, S.E. and Poland, B. (2005), "Family, friend or foe? Critical reflections on the relevance and role of social capital in health promotion and community development", Social Science and Medicine, Vol. 60 No. 12, pp. 2819-2832.

Wasko, M.M. and Faraj, S. (2005), "Why should I share? Examining social capital and knowledge contribution in electronic networks of practice", MIS Quarterly, Vol. 29 No. 1, pp. 35-57.

Wetter, D.W., Kenford, S.L., Smith, S.S., Fiore, M.C., Jorenby, D.E. and Baker, T.B. (1999), "Gender differences in smoking cessation”, Journal of Consulting and Clinical Psychology, Vol. 67 No. 4, pp. 555-562.

Wiertz, C. and de Ruyter, K. (2007), "Beyond the call of duty: why customers contribute to firm-hosted commercial online communities", Organization Studies, Vol. 28 No. 3, pp. 347-376.

Williams, L.J., Cote, J.A. and Buckley, M.R. (1989), "Lack of method variance in self-reported affect and perceptions at work - reality or artifact", Journal of Applied Psychology, Vol. 74 No. 3, pp. 462-468.

Yu, Y., Hao, J.X., Dong, X.Y. and Khalifa, M. (2013), “A multilevel model for effects of social capital and knowledge sharing in knowledge-intensive work teams", International Journal of Information Management, Vol. 33 No. 5, pp. 780-790.

Zhang, M. and Yang, C.C. (2015), "Using content and network analysis to understand the social support exchange patterns and user behaviors of an online smoking cessation intervention program", Journal of the Association for Information Science and Technology, Vol. 66 No. 3, pp. 564-575.

Zhang, X., Liu, S., Chen, X. and Gong, Y. (2017a), "Social capital, motivations, and knowledge sharing intention in health Q\&A communities", Management Decision, Vol. 55 No. 7, pp. 1536-1557.

Zhang, X., Liu, S., Deng, Z.H. and Chen, X. (2017b), "Knowledge sharing motivations in online health communities: a comparative study of health professionals and normal users", Computers in Human Behavior, Vol. 75, pp. 797-810.

Zhao, J., Ha, S.J. and Widdows, R. (2016), "The influence of social capital on knowledge creation in online health communities", Information Technology and Management, Vol. 17 No. 4, pp. 311-321.

Zhou, T. (2019), "Understanding users' participation in online health communities: a social capital perspective", Information Development, Vol. 36 No. 3, pp. 403-413.

\section{Corresponding author}

Chenglong Li can be contacted at: chenglong.li@utu.fi
Knowledge sharing in smoking cessation $\mathrm{OHC}$ 
INTR 32,7

\section{Appendix A.}

\begin{tabular}{lll}
\hline Construct & Measurement items & Reference \\
\hline Knowledge sharing & KS1: I frequently participated in knowledge sharing activities & Hsu et al. (2007)
\end{tabular}

(KS)

\section{8}

Commitment (CO) within the smoking cessation $\mathrm{OHC}$

KS2: I usually spent a lot of time in knowledge sharing activities within the smoking cessation $\mathrm{OHC}$

KS3: I usually shared information with others in the smoking cessation $\mathrm{OHC}$ actively

KS4: I usually involved myself in discussions of various topics within the smoking cessation $\mathrm{OHC}$

$\mathrm{CO}$ : I was proud to belong to the smoking cessation $\mathrm{OHC}$

$\mathrm{CO}$ : I felt a sense of belonging to the smoking cessation $\mathrm{OHC}$

CO3: I cared about the long-term success of the smoking cessation $\mathrm{OHC}$

Reciprocity (RE) RE1: I knew that other members would help me, so it is only fair to help other members

RE2: I knew that someone would help me if I were in a similar situation

Shared language SL1: The members of the smoking cessation OHC used common (SL) terms

SL2: The members of the smoking cessation OHC used understandable communication patterns during discussion SL3: The members of the smoking cessation OHC used understandable narrative forms to post messages or articles SL4: The members of the smoking cessation OHC were always on the same frequency when we talked about smoking cessation

Shared vision (SV) SV1: Members of the smoking cessation OHC shared the vision of helping others solve their smoking problems

SV2: Members of the smoking cessation OHC shared the same goal of supporting each other

SV3: Members of the smoking cessation OHC shared the same sense that helping others was pleasant

Social ties (ST) ST1: I maintained close social relationships with some members of the smoking cessation $\mathrm{OHC}$

ST2: I spent a lot of time interacting with some members of the smoking cessation $\mathrm{OHC}$

ST3: I knew some members of the smoking cessation $\mathrm{OHC}$ on a personal level

ST4: I was in frequent communication with some members of the smoking cessation $\mathrm{OHC}$
Liang et al. (2011)

Wasko and Faraj (2005)

Chiu et al. (2006)

Chiu et al. (2006)

Chiu et al. (2006)
Table A1.

Measurement items and their sources 